After friendship

Dr Mary Healy

Froebel College University of Roehampton

Roehampton Lane

London SW15 5PJ

Mary.Healy@roehampton.ac.uk 


\begin{abstract}
The loss of friendship can be a frequent occurrence for children as they explore their social worlds and navigate their way through the demands of particular relationships. Given that friendship is a relationship of special regard, and associated with a particular partiality to our friends, the ending of friendship and the subsequent interactions between former friends, can be difficult areas for schools to deal with.

Whilst there has been considerable research on the formation and maintenance of friendship, a consideration of what happens after friendship has had surprisingly limited attention. Much of our current understanding of issues on moral behaviour fails to fully address the positioning of former friends in our moral thinking particularly as regards matters arising from the priority of attachment.
\end{abstract}

Recent empirical research seems to indicate that the memory of prior encounters has a far greater influence on future reciprocal exchanges (such as those found in friendship) than previously accepted. This paper considers suggests that this view of memory can be played out in two contrasting ways. First, a prudential view suggests that as our former friends were previously given access to our intimate secrets and confidences, self-interest would seem to indicate that we treat them well. Secondly, a residual duties view suggests that some obligations remain after the friendship has ended based on the history of the relationship. Finally, I then draw out some of the implications this may have for schools and the education of children.

Key words: Friendship, special obligations, residual duties, former friends, priority of attachment. 


\section{After friendship}

\section{Introduction}

The relationships we are in can make a difference to how we feel, how we act or how we justify our actions. Imagine someone passes your office, reporting that someone had collapsed in the building and was hurt. Your first response may be sympathy for a fellow human in distress: perhaps asking if they are all right, or if there is anything you can do to help, but you are unlikely to be moved to do anything beyond this (unless you are a first aider). Now swap the unknown person for your best friend: the chances are you would feel more concern and might immediately go to check on them. Now swap your best friend for someone who used to be your best friend: would that make a difference in your responses? You might go beyond just feelings of general sympathy but not go running to see if they were OK. Given that this person was once your best friend, that you had a deep enduring relationship of affection and mutual care at one point, how do you now situate the relationship within a discourse of partiality and obligations between persons emanating from special relationships? In a more philosophical vein: what (if anything) remains after friendship to justify treating a former friend differently to a stranger?

Although there is a considerable literature on the formation and maintenance of friendship (for example Buhrmester and Furman, 1987, Selman, 1980) our understanding of what happens after friendship has had limited attention in both empirical and theoretical studies, let alone how schools might engage with the subject. Where research does exist in the literature specifically on former friendship, it tends to be mainly within the domain of antipathetic relationships or domains arising from 'hostile friendships' (Card, 2007). This is curious in view of the fact that tracing former friendships, whether to catch up on their progress or reconnecting through reunions, 
are increasingly common activities. The growth of social media sites such as Friends Reunited or Facebook have made such reconnecting with former friends easily achievable.

Friendship undoubtedly has particular pertinence in the context of childhood. Psychology teaches us that most children 'try on' different friendships, particularly during the period of identity exploration in middle childhood and adolescence, thus experiencing a higher level of friendship change than adults. For very young children, this 'loss of friendship' can be a frequent occurrence (Bowlby, 1980, Bauminger et al., 2008), often resulting in higher levels of vulnerability to the ensuing distress when the friendship ends. ${ }^{1}$ Adults who subsequently advise on conduct, whether as educators or as parents/carers, can often find this 'churn' of friendship bewildering in its frequency and often lack confidence as to how to discuss such matters. But the loss of friendship can have other repercussions: it can also entail the loss of the support systems created by the pair and it is this element in particular that I want to address.

Whilst it is commonly accepted that we would do more for our friends than for others (the priority of attachment), I want to suggest that it may be helpful to enrich this critique: that in some circumstances, our understanding of the demands of particular attachments may need to consider the ties of former friends - those who stand at a midpoint between our current ties and those of strangers. More specifically, I seek to restore interest in the possibility of some element of 'residual duties' surviving the end of a friendship (Dixon, 1995) by drawing attention to the Aristotelian claim that

\footnotetext{
${ }^{1}$ Indeed a wealth of empirical research has drawn links between terminated friendships and victimisation, bullying and malicious gossip between previous friends SNELL, P. A. \& ENGLANDER, E. 2010. Cyberbullying victimization and behaviors among girls: applying research findings in the field. Journal of Social Sciences, 6, 510-514, BURMAN, M. 2004. Turbulent talk: Girls' making sense of violence. In: ALDER, C. \& WORRALL, A. (eds.) Girls' violence: Myths and realities. New York: State University of New York Press.
} 
we should treat our former friends well in memory of the intimacy we once shared (Aristotle NE, 1165b30-35).

To achieve this, we first need to clarify the concept of 'friendship' itself and to distinguish the group we refer to as 'former friends'. Then, the obvious next step would be to identify the problem of friendship within the context of competing ethical theories and to understand the challenge it poses for those theories. Following this exposition, we can then consider the 'specialness' of friendship within the discourse of special or negative obligations and role expectations. Drawing on rich recent empirical and philosophical literatures, I explore the role of memory and suggest two ways of conceptualising how some form of priority of attachment might survive amongst former friends: a prudential view and a residual duties view. Finally, these discussions then lay the foundations for drawing out ways in which this has implications for schools and the teaching of children.

\section{Understanding friendship}

The contemporary view of friendship often portrays it as a fairly loose relationship that lacks the formal structure and specific sets of rights and obligations associated with explicitly contractual relationships. The Aristotelian tradition, in which much of philosophical thinking on friendship is rooted, makes a good starting point from which to explore some of the more influential strands of thinking in this area in that it promotes friendship as a particular relationship associated with virtue or virtuous behaviour, as a vehicle for moral self-examination and/or a source of moral excellence (Aristotle NE). As no two friendships are exactly alike (each pair 'negotiates' their particular bond, choosing the level of their involvement in the life of the other), it can 
be difficult to find a philosophical account of friendship that enjoys universal acceptance, yet there are broad areas accepted as particularly important.

First, friendship is commonly agreed to entail a particular care and concern for each other's well-being. This affection, whilst important in a friendship, cannot be seen as sufficient - it would be possible for two people to feel affection for each other and yet never to develop a friendship. Yet as Annis points out, it would be hard to imagine two people that claim to be friends who did not like each other at all (Annis, 1987). Secondly, friendship is action-generated - being friendly, actively trying to benefit the other and 'good will', a liking or loving emotional involvement in some way in the lives of each other (Aristotle NE, Pangle, 2003). It is this element that is often argued to place special demands on us in ways which are typically denied to those outside of the relationship: that friendship contains a "behavioural disposition to promote each other's well-being" (Jeske, 1997, p. 53). Thirdly, there is the expectation that the bond (and the actions that support the bond) is reciprocated in some way (it is mutual). Both persons have to acknowledge the friendship; unlike love, which can be unrequited, friendship requires two. The final point to make here is that friendship is not instant: it takes time to enable the development of a 'rich baggage' of shared memories and experiences, as well as knowledge of the character and values of the other person that we associate with friendship (Stern-Gillet, 1995).

Common experience teaches us that not all friendships can be enduring: our lives are too short to be able to devote the time needed to sustain all. This potentially leaves many lost friendships with people who at one time, were special to us. The former friends I specific want to consider here are those with whom we have previously experienced a very close friendship ('best friendship') and because we have been good friends in the past, we have spent time together, shared secrets and activities, 
cared for and been cared about. Yet for some reason, the friendship has faded and we no longer do these things with them nor feel about them the same way. Here, the term 'former' acts as a modifier - we were friends but are so no longer. The friendships have lapsed, not necessarily completely ended for all time; these former friends have shared a past, but lack a 'present': it does not always block off a future or the possibility of friendship being revisited. Given that my primary interest is to draw attention to the positioning of these former friends in discourses of 'priority of attachment', the next step needed is to clarify why friendship is seen as problematic for moral theory.

\section{The problem of friendship}

The problem of friendship is usually voiced in terms of how we integrate the demands of friendship into our wider moral thinking. In a nutshell, if we have genuine reasons to treat friends differently to others, it would follow that some claims might be in tension with other claims of moral behaviour. So ingrained in our psyche is the belief that we owe more to those with whom we share particular relationships than we do to strangers, that we rarely view them as duties at all. This belief that friendship is a relationship of special regard, and that we owe more to our friends and hence should treat them better than non-friends, is considered to be common across many cultures (Bell and Coleman, 1999). Yet the preference found in friendship has also been accused of a particular injustice in that it argues for a partiality to our friends purely on the grounds that they are our friends and thus ignoring issues of need or desert.

Arguments over this 'priority of attachment' and the import of claims for persons as moral agents have been well rehearsed in much of contemporary philosophical theory in recent years. Traditionally, this has resulted in numerous moves to view friendship as a basic moral relationship (Blum, 1980, White, 1999), to see personal 
relationships as holding particular problems for Kantianism and consequentialism or even debates over the compatibility of some moral theories with the claims of friendship. The complexity of the debate surrounding this area can sometimes appear to represent a polarity of positions so diametrically opposed to each other as to be irreconcilable. For example, impartialist theories of obligation (such as that of Kant) purport that our entitlements and rights are not contingent on our roles or relationships to others. For instance, a strict consequentialist would argue that my friend's wellbeing should be no more or less intrinsically valuable than anyone else's well-being. Just because someone stands in relationship to me as a friend, should not then imply that I should have special obligations to that person over and above obligations to people in general. The problem here, as philosophers such as Railton argue, is that being a friend entails acting out of concern for the friend in some way, thus seeking their good and not just the general good (Railton, 1984). A strict Aristotelian view, on the other hand, might argue that we should take special care of our friends because they are deserving of special concern by virtue of being a suitable object for such concern. The problem with this is that it would seem to leave us with no obligations to our 'not-so-virtuous' friends, which seems to contradict our commonsense experience of friendships. Others approach the problem by arguing that 'special relationships' are indeed the basis or grounds for legitimate expectations between those involved: that friendship requires a special kind of concern for our friends and a particular partiality towards those so positioned in our regard. In other words, the relationship itself demands that friends should promote each other's well-being in ways greater than with those of strangers (have 'priority of attachment'). 
Much of the recent philosophical interest in friendship frames it as a voluntary relationship, lacking a formal legal or contractual framework that specifically identifies particular 'duties' or 'requirements'. To take just one example: consider the way in which family law reaches out beyond the creation of the family unit to address the obligations between members even after the relationship ends (divorce and maintenance settlements/division of goods/child access/inheritance etc). As there are no legally enforceable obligations put on friendship by the state, "any obligations arise from the parties themselves" (Rosenbury, 2007, 203). Friendships are clearly not as regulated as other personal relationships (such as marriage) hence any resulting commitments may be less obvious when they fail. Indeed, it is often claimed that part of what has value in friendship is precisely that it is not upheld by a variety of laws and regulations.

A veritable mountain of philosophical literature has evolved through attempts to argue whether or not some personal relationships might contain within them particular moral obligations such that to be in that type of relationship requires a particular preference for those inside of the relationship over those who remain outside. Much of this has prompted philosophers to ask broad questions about the nature of the 'priority of attachment', encompassing particular understandings that have yet to be fully or systematically explored.

Few friendships have points at which the friends explicitly make promises or undertakings to each other, yet in entering into friendship we are somehow agreeing to something that is 'joint', sometime referred to as a 'shared life'. Nehamas describes it thus: "Friendship, like every kind of love, is a commitment to the future, based on a promise of a better life together than either one of us can have alone" (Nehamas, 2010, 278). Gilbert suggests that some commitments are best understood as 'joint 
commitments' and as such "this type of order, in so far as it needs to be 'pronounced', need not be voiced" (Gilbert, 1999 149). Does friendship fit within this framework? Current understanding of a 'joint commitment' requires that both parties have to rescind it together - neither party can rescind it alone. Yet friendship can be rescinded by either individual without the knowledge or permission of the other, as can a 'downgrade' from best friend to casual friend or acquaintance. Richard White, nevertheless, argues that there is "still an implicit obligation that is an organic part of the relationship itself, and which would still be there even if it were not recognized by one or other of the friends" (White, 1999 81-2). Three interlinked literatures have evolved that may prove invaluable in thinking our way through the quagmire of arguments in this area: special obligations, negative duties and role expectations.

\section{Special obligations}

One branch of philosophical scholarship has traditionally argued that we may have 'special obligations' to those with whom we stand in particular relationships or with whom we are tied. The obligations are 'special' as they are not to people in general they can only be held by those in that relationship. Nevertheless, such obligations/duties are assumed to be contingent to continuance of friendship: should the friendship end, these duties are considered to be cancelled.

Philosophers such as Dworkin reject arguments claiming that just by belonging to a group, one assumes particular obligations as a member with 'associative obligations' (Dworkin, 1998, 196). As Dworkin points out, friendship does not form in a particular consensual act, but through:

... a series of choices and events that are never seen, one by one, as carrying a commitment of that kind... We have friends to whom we owe obligations in virtue of a shared history, but it would be perverse to describe this as a history of 
assuming obligations. On the contrary, it is a history of events and acts that attract obligations.

(Dworkin, 1998, 197)

In a similar way, Telfer suggests that the mutual endorsement or consent to friendship becomes enshrined in shared practices over time - these define the commitment each makes to the other (Telfer, 1970). Being self-assumed, this can result in a limited shared understanding of what each will do for the other.

Other philosophers, such as Stocker, point out that friends do not see their behaviour as being based on duty at all (Stocker, 1981). If there were no special obligations or duties between friends, we would have to claim that the duties we undertake to please our friends are neither more nor less other than the duties we have to all other people: what would differentiate them would be merely the opportunity to treat all the same way. This would mean that being a friend would not be a special reason for preference as such, but more an opportunity to exhibit the virtues we owe to all.

\section{Negative duties}

A further development of this argument has suggested that to become a friend with someone is to enter into an implicit agreement not to treat each other in particular ways. To be a friend with someone is to enter into an implicit agreement not to treat each other in distinctive ways and that some ways of behaving are considered morally incompatible with friendship. There is considerable philosophical precedent for taking such a stance: for example, Aristotle claimed that lying, cheating or deceiving are all somehow worse if done to a friend (Aristotle NE). This line of argument has notably been developed in the work of Cocking and Kennett, who suggest that friendship can serve more to exclude certain types of behaviour rather that to promote particular actions (Cocking and Kennett, 2000). In a similar vein, Hurka has argued that 
alongside positive duties to promote the wellbeing of our friends are also found negative duties: that we also have duties not to hurt, lie or break promises to our friends going beyond those of duties to strangers (Hurka, 2013).

\section{Role expectations}

Scholars such as Hardimon consider whether our reasons to prioritise are social expectations drawn from the role itself, leading to arguments that such role obligations might be central to morality (Hardimon, 1994). Most social roles play out in a variety of ways: in my role as teacher, I may be advising, admonishing, praising, encouraging, evaluating amongst many other tasks, each of which depends on the context in which it arises. Many interactions are governed by the social conventions of the role: the doctor and patient; the employer and employee; the shop salesperson and the customer. Some of these interactions are codified as to the boundaries of legally enforced expectations for the interactions (for example, the interactions of employers and employees are subject to the respective employment laws); other interactions may have less formal codes of ethics governing behaviour.

Particular role expectations often pertain to the way we expect people to behave, whether or not they follow the expected social norms for that role. It is undoubtedly true that having an expectation usually means we have reasons for the belief that things will go a certain way. These understandings of what it is to occupy the role often include assumptions of what others occupying that role would do. For example, we expect parents to do things for their child that we would not expect them to do for all other children: perhaps reading bedtime stories; intimate care giving etc. Whilst we may not explicitly promise particular actions or behaviours to our friends, it could be argued that friendship as a social role has particular elements - we expect 
certain behaviours and attitudes from our friends as being symptomatic of that kind of relationship, but also includes my expectation of this particular person in that role.

While there are arguably some flaws in this reiteration of the problem, I want to suggest the theoretical landscape becomes considerably blurred with applied in practice. Former friends can no longer be simply classified as friends (hence any expectations or obligations arising from a generalised 'priority of attachment' between the pair may no longer strictly apply), but they seem to be in a different category to those of complete strangers in that we knew (and loved) them once. Role obligations similarly offer little insight - there is no obvious identifiable social role of 'being a former friend'. ${ }^{2}$ So it is unclear then as to how we might explain, and later accommodate, our tendencies to differentiate between former friends and unknown others.

\section{After friendship}

Even if we accept that our friends are 'special' to us and thus deserving of better treatment than 'non-friends' from us, this does not automatically mean that they will remain special in our eyes for all time. In what follows, I want to suggest that there may be situations for some former friends in which the previous relationship 'still counts for something'. Empirical research seems to suggest that we do indeed make such choices: that friendship dissolution is not always complete. Bowker, for example, suggests that some friendships can be subject to a 'downgrade', evolving into a less close, less intimate relationship over time (Bowker, 2011). What is of interest here is that these downgraded friendships hold the possibility of a further 'upgrade' in the future. The overall picture that emerges is that there may be gradations of attachment

\footnotetext{
${ }^{2}$ This does not, of course, rule out the possibility of there being one at a future date.
} 
that survive some 'downgrades' and these may give good reasons to treat some former good friends differently to non-friends.

Aristotle suggests that we should keep hold of the memory of the earlier intimacy beyond the dissolution of the friendship (Aristotle NE) and treat them well in memory of the intimacy we once shared: that friendship, being a form of love, requires us to treat our former friends better than strangers:

Surely, he then, behave no otherwise towards him than he would if he had never been his friend? Surely he should keep a remembrance of their former intimacy, and as we think we ought to oblige friends rather than strangers, so to those who have been our friends we ought to make some allowance for our former friendship, when the breach has not been due to excess of wickedness" (Aristotle NE, 1165b30-35)

What should be noticed first is that friendship within the Ancient Greek world was a very different relationship to that which we are accustomed to today. ${ }^{3}$ It was seen as very much a public matter and as part of a wider interpretation of the concept of philia (Brunkhorst, 2005). These obligations of 'friendship', seen within a dense network of familial obligations and alliances of leading families of other cities (xenoi), could not only be inherited be passed on through the generations, could lapse and be reactivated, but the obligations and ties of loyalty that bound families together could override other obligations (Herman, 1987). Former friendships could literally oblige us to make allowance for the previous relationship. Given that we no longer operate within a framework of such ritualised friendship, this position involves complexities that need further clarity. Recent research into the role of memory in partiality is beginning to provide a serious attempt to restore interest in this area.

The role of memory

\footnotetext{
${ }^{3}$ I am indebted to Dr Oliver Belos for this reminder.
} 
Recent research into the evolutionary origins of human friendship seems to suggest that reciprocal exchanges (such as those found in friendship) are far more dependent on memories of prior encounters than previously noted. Seyfarth and Cheney, on finding that several patterns seemed to recur across species, surmised that the best predictor of future engagements was a previous history of events, reciprocities and engagements (Seyfarth and Cheney, 2012). Learning from the experience of previous interactions, they argue, gives us a way of anticipating the future behaviour of the other. Sutton, on the other hand, suggests that memory "labels a diverse set of cognitive capacities by which we retain information and reconstruct past experiences, usually for present purposes" (Sutton, 2012), describing it as an important way in which our past experiences ‘animate' our present actions.

Friendship enables the development of the 'rich baggage' of shared memories and experiences, as well as knowledge of the other person, which may not be entirely lost should the relationship fade or end. These memories are often impregnated with emotions, connecting our present self with our past experiences and actions in some way. In remembering an event, we often call to mind particular images: the picnic in the park with friends; the first conference paper given; the death of a parent. These memories of past relationships, and the emotions generated by the memories, are available to us in a way that is not available with strangers, thus we may be more likely to embrace the predictable regularities of former friendships. After all, the argument goes, with former friends, we knew them once: we knew their character and had loved and trusted them.

However, we can often be unaware of the selective (and inaccurate) nature of memory. Most cognitive and developmental psychologists have long accepted that memory is fallible: the things we choose not to remember, the 'gaps' in our 
recollections, the asymmetry in which two people can remember the same event. Whilst we may indeed be referencing or drawing on a past history of events with our former friends that leads us to trust in and anticipate the future actions of our friends, we also need to caution against over-reliance on particular recalled memories alone. First, there might be some unfavourable history with the former friend that led to the demise of the friendship, in which case we may look backwards with the proverbial rose-tinted glasses, mis-remember what swines they were, how they made us miserable, and fail to recognise that we had good reason to abandon the relationship. Secondly, just as easily as mis-remembering, we can also forget events or be selective of memories. Thirdly, and most importantly, to see friendship purely in terms of reciprocal exchanges seems to misunderstand the nature of friendship itself: friendship 'support' is not dependent on a build up of previous debts from one to the

other. Unlike favours between persons, in friendship these are not on a 'tit-for-tat' basis: doing a favour for a friend is just what friends do. So how might some form of priority of attachment survive amongst former friends?

\section{The prudential view}

At one end of the spectrum (let's call this the prudential view) we might find those who caution that former friends are uniquely positioned (because of the former friendship) to place us in some form of 'danger' and thus become cautious in our treatment of them. If that friendship can be demonstrated through a mutual intimacy of privileged information not available to others (and that there is an expectation of confidentiality between friends not to disclose these confidences), if the friendship ends, that expectation may no longer hold and our secrets may then become common knowledge or used against us. Such a prudential view argues that given that our 
former friends have access to our intimate secrets and confidences, self-interest would seem to indicate that we treat them well.

Even young children will share secrets and confidences and, as many teachers will acknowledge, when friends fall out, it can be the breaking of these confidences and sharing of another's secrets that causes the most distress. ${ }^{4}$ Indeed, the breaking of confidences can even be a way of gaining access to a new group (a form of 'membership fee' paid to demonstrate the shift in loyalties). But if our concern about how we treat former friends is solely based on the danger that the other may hurt us or break confidences, it seems unsatisfying on its own as a moral response, suggesting a deep self-centredness in our dealings with former friends.

\section{Residual duties}

At the other end of the spectrum we might find those who argue that not all expectations or obligations end with the friendship - that some might survive, albeit in adapted form. Dixon purports that he has good reason to prioritise his former friend over a stranger (all other things being equal) in that former friendships create extra moral ties that "are not precipitately dissolved by our unfortunate estrangement" (Dixon, 1995, 79). What these 'residual duties' might be is never explicitly drawn out by Dixon, but it may leave us with some 'wriggle room' to explore. It is worth stressing that Dixon does not suggest that all abandoned friendships should come with complete residual duties: indeed, he explicitly argues that these might diminish to zero if the friendship ended because of the unforgivable behaviour of the friend (Dixon, 1995). ${ }^{5}$

\footnotetext{
${ }^{4}$ This plays out in increasingly problematic ways with the use of multiple technologies as the medium through which we socialise and maintain our friendships: from posting rumours seen by multiple others, to passing around abusive or humiliating messages via social media to 'revenge porn'.

${ }^{5}$ A point also made by Aristotle NE
} 
Similarly, he argues, any 'residual ties' would be far weaker than ties to current friends, given the numerous relationships we form and exit from during the course of our lives.

This approach can be revisioned in the light of the research on memory cited earlier. First, our former friend was a person who we saw as a 'second self' - we were deeply invested in one another; they were important to us and we cared deeply for their well-being to the extent we were willing to sacrifice some of our good to help them achieve their goals. Being a former friend indirectly references this history built up in the friendship and thus anything that may survive would undoubtedly have to depend on the nature of the history shared and on how it ended. Secondly, any 'residue' emanating from the previous friendship would have to come with a degree of proportionality: such 'residual duties' might persist after a reasonably short estrangement (hence we can sometimes pick up with friends we have not seen in some time, almost as if we have never been apart) but might dissipate completely after several decades. We may have valid reasons, underpinned by the ties and bonds of loyalty and affection found in friendship, to prioritise former friends over strangers in the first throes of friendship dissolution (during early downgrade), but there must come a time at which this fades into insignificance. In drifting further and further apart, we may find we owe them fewer duties and, over time, perhaps no 'residual duties' at all. This seems to suggest that there is a period of time during which we move from 'having special obligations' to 'not having special obligations' that may counterbalance the move in the opposite direction in the formation of friendship.

Dixon clearly suggests that completely abandoning a former friendship as now counting for nothing at all would be to question the depth and authenticity of the previous friendship (Dixon, 1995). This, he argues, would be to devalue both persons, as both had previously invested of themselves in the friendship and would now be 
disowning or ignoring that part of themselves the friendship may have contributed to forming. It is this element, I want to suggest, that gives us a starting point for how we might unpick the implications of this for schools.

\section{The role of schools}

School leaders and policy makers are undoubtedly beginning to pay more attention to issues of friendship, but not always for the most admirable of reasons. A plethora of recent governmental reports have highlighted social relationships as being crucial to improve the social well-being of pupils, who in turn achieve better academically in their readiness to learn and success criteria (for example DfE, 2015). In other words, positive relationships with others are acknowledged as having an enduring impact on future attainment. Whilst the attention given to peer relationships and friendships are, in the main, positive moves, the utilitarian reasoning used, connecting learning and positive peer interactions with higher standards, raise concerns that friendship then risks becoming seen as a 'skill' to be practiced and fine-tuned, which then risks missing the fundamental role it plays in our personal well-being. ${ }^{6}$ Indeed, the sheer volume of new directives to this end (the pragmatic appeal of market expediency), make it increasingly difficult to sustain a belief in the value of friendship in our everyday lives.

Before proceeding further, it is important to note that I am not proposing a blueprint for practice here: it is not my intention to suggest 'friendship lessons', neither do I call for friendship to make a direct appearance on the school curriculum, not even for schools to develop even more policy documents. Schools are already responsible for much of the social and emotional development of their pupils, and all of the above

\footnotetext{
${ }^{6} \mathrm{I}$ am indebted to the anonymous reviewers for reminding me of this.
} 
(except for the paperwork) are already in place in many ways. ${ }^{7}$ My contention is that 'after friendship' requires reinterpreting and enacting these existing commitments and obligations beyond suggestions that schools should pay more attention to friendship or give caring support to children with their social development (both reasonable ideals).

One way in which we can contribute towards a deeper understanding of the issues requires us to start from the fact that what happens after friendship is inevitably going to be bound up with the way in which it ends. After all, it is the aftermath of previously good friendships, those friendships that end badly, that research identifies as particularly problematic for schools. In some circumstances, the ill-will that each feels for the other might make being together, let alone revisiting the relationship, impossible. In which case, we may be quite justified as educators in separating 'frenemies' as needed, at least whilst emotions 'run high'.

Many teachers still feel that actively promoting friendships goes beyond their professional responsibility (Hollingsworth and Buysse, 2009) and some can be hesitant on-lookers as friendships start to fade. This can at least partly be explained by the way in which friendship has become a private matter as a strictly voluntary relationship in which teachers feel reluctant to intrude. Whilst teachers believe that children's social and emotional development is important, many believe they have limited influence. Yet there is much in their existing practice that already feeds into this area from dealing with disruption arising from difficult friendship endings to finding companionship for the lonely child on the playground.

\footnotetext{
${ }^{7}$ For example, the obligations to promote the spiritual, moral, social and cultural development of pupils (SMSC) as outlined in section 78 of the Education Act (2002).
} 
So what more can (or should) schools and teachers do? The following interlinked points may help us establish further ways in which we can support children with learning to live with former friends. First, social and emotional well-being is becoming well established in many schools in the UK as both a commitment and a priority. Subject content in areas such as PSHE is often seen as a way to address these difficult issues surrounding pupil well-being, in changing attitudes and dispositions and thus enabling children to live happier lives. Secondly, it seems reasonable to assume that many children enter school already forming ideas on a variety of issues and values including early friendships. Part of the role of the school has always been to build on and supplement the range of values that pupils enter with, supporting children in understanding and applying their growing sense of values (Halstead and Taylor, 2000). This includes their understanding of and value given to social relationships appropriate to their age and development. Thirdly, there is already a considerable empirical literature looking at 'what works' (for example, Ellis and Zarbatany, 2007, Proulx and Poulin, 2013, Weller, 2007), much of which considers the conditions needed for relationships to be sustained. All of the above suggest that schools actively valuing friendships, teaching children how best to sidestep minor conflicts, how to respond to transgression, or how to achieve reconciliation ${ }^{8}$ and encouraging children to behave with civility to former friends may all play a part in this.

Psychology has long drawn links between the development of the emotions, socialisation and particular relationships (Denham, 1998), and if the research suggesting memory has a deep emotive aspect to it is justified, particularly when linked to the reciprocal exchanges found in friendship, this has to be carefully interpreted

\footnotetext{
${ }^{8}$ Whilst there is the possibility of reconciliation between friends after friendship, this cannot be taken for granted; neither can it be insisted on.
} 
within the realm of childhood. While we may expect most adults and many teenagers to behave with reasonable civility to former friends (even to those who may have hurt or abandoned them) learning to associate with basic moral respect for former friends may not be immediately achievable for young children in the same way. The shared memories and experiences that formed the basis of the friendship may not be as available to them, nor as easily understood or construed as with adults, and it is likely to be this element that children may need support with in order to develop the capacity to verbalise and reflect on their relationships.

But we must also remember that schools are not the only agency influencing children in such issues; when it comes to young children, parents play a crucial role in supporting enduring relationships and attitudes to former friends. Family members undoubtedly influence friendship and peer social networks in such areas as availability, travel, arranging play-dates, all of which tend to affect children's choices when young. Most parents learn to recognise that conflict and the ensuing break-ups between good friends can be temporary (that childhood friendships have an 'ebb-andflow' even in the best of them), and many wisely side-step such issues, concentrating on more positive ways of helping children to socially interact in supportive environments. Nevertheless, research is starting to identify ways in which parents and schools can work together to support the development of relationships. For example, Hollingsworth and Buysse (2009) found that parents of very young children (3-5 year olds) with developmental delay would support their child's friendships by simple strategies such as talking specifically about the friend thus keeping the friend 'in mind' or directly greeting them in school. Teachers, for example, would promote friendship by setting up the social environment to help friends to interact, through careful choice of shared activities and the coaching of positive interactions. More complex strategies, 
such as directly helping children to resolve conflict, giving children ideas on what or how to play, were used by both teachers and parents in the research with some success.

Just as it takes time to build a friendship, it can also take time for a friendship to end. Short of those that end in conflict, many friendships that do not survive tend to slowly drift rather than atrophy. Not all ended friendships come with full residual duties to our former friends and these can fade over time; neither can all be reinvigorated (even for children) despite the pleas of parents or teachers to 'make friends again'.

\section{Conclusion}

Whilst it is commonly accepted that we would do more for our friends than for others, I have argued that it may be helpful to enrich this critique: that our understanding of the demands of particular attachments need to expand to consider those who stand at a midpoint between our current ties and those of strangers. I now want to suggest that making such an allowance for a former friendship, keeping a remembrance of our former intimacy, reinforces and builds on commonly held views in philosophy of friendship in several different ways as intimated earlier.

First, the lives of some persons do seem to be special to individuals in some way and to differing degrees, giving rise to reasons for partiality and it is not clear how any plausible moral framework could argue away from this in its entirety. For friendship to last, we need some sense of favouring those who are special to us. Indeed, many of these reasons to prioritise some might not exist (or be explained away) were it not for the existence of the relationship. Such obligations in some relationships may be cumulative over time, depending on both the individuals' involvement in each other's lives. But these obligations can fade over time as relationships are 'downgraded' 
resulting in a limited partiality towards former friends. However, when it comes to the friendships of children, the cumulative partiality of friendship may be 'truncated' by the time-span of the friendship and the age of the child. Similarly, downgrades may be more likely as very young children 'try on' different friendships (See for example Ahn (2011))

Secondly, taking away the status of current friendship could still leave a layer of 'affective care' ${ }^{\prime}$ that still has the appearance of duties and expectations. Care has an emotional aspect as well as a behavioural aspect and some emotional ties are not so easy to lose. While I may no longer actively seek to promote the well-being of my former friend in the way I previously might have done, I might still care what becomes of him or seek to protect him from harm in ways over and above that of strangers. In other words, we may wish them well more than we might someone we do not know, but we may not be so willing to sacrifice our own good as easily as we might within a current deep friendship. This gives us further good reason to promote the social education of children.

Thirdly, much of social psychological theory suggests that friendships contribute in some way to who we are as a person and to who we may become. Indeed, a veritable mountain of research has amply demonstrated the importance of this in childhood. Some social relationships (such as friendship) undoubtedly strongly influence how we define and see ourselves; some of these past identities can linger on and still contribute to how we see ourselves now (Ebaugh, 1988). Whilst we can 'unfriend' (for want of a better term) someone from our lives so that they are no longer part of our present or future, we cannot edit them entirely from our past. Encouraging

\footnotetext{
${ }^{9}$ The behavioural disposition to promote each other's well-being as described by Jeske
} 
civil relationships with our estranged friends, being grateful for our former friendships and respecting differences then augment and enrich the school ethos.

Finally, not all former friendships are the same: some will inevitably be closer in our affection than others will. Not all friendships survive in perpetuity - some may end badly; others may fade away, having run their course. Yet for a few, the former friendship may indeed generate reasons for treating the former friend more generously than complete strangers - depending on the depth and nature of the original friendship and the reasons for its demise.

\section{Bibliography}

AHN, JUNEHUI (2011) "You're my friend today but not tomorrow": Learning to be friends among young U.S. middle-class children. American Ethnologist 38.2, pp. 294-306.

ANNIS, DAVID ( 1987). The meaning, value, and duties of friendship, American Philosophical Quarterly, 20.4 pp.349-356

ARISTOTLE The Nicomachean Ethics (Oxford, Oxford University Press)

BAUMINGER, NIRIT., FINZI-DOTTAN, RICKY, CHASON, SAGIT \& HAR-EVEN, DOV (2008) Intimacy in adolescent friendship:The roles of attachment, coherence, and self-disclosure, Journal of Social and Personal Relationships, 25.3, pp. 409-428

BELL, SANDRA \& COLEMAN, SIMON (eds.) (1999) The anthropology of friendship (Oxford, New York: Berg)

BLUM, LAURENCE (1980) Friendship, altruism and morality (London; Boston, Routledge and Kegan Paul)

BOWKER, JULIE (2011) Examining two types of best friendship dissolution during early adolescence, The Journal of Early Adolescence, 31.5, pp.656-670

BOWLBY, JOHN (1980) Attachment and loss: Vol. 3. Loss (New York, Basic Books)

BRUNKHORST, HAUKE (2005) Solidarity (Cambridge, Massachusetts, MIT Press)

BUHRMESTER, DUANE \& FURMAN, WYNDOL (1987) The development of companionship and intimacy, Child Development, 58.4, pp.1101-1113

BURMAN, MICHELLE (2004) Turbulent talk: Girls' making sense of violence. In: C. ALDER \& A. WORRALL (eds.) Girls' violence: Myths and realities (New York, State University of New York Press)

CARD, NOEL (2007) "I hated her guts!": Emerging adults' recollections of the formation, maintenance, and termination of antipathetic relationships during high school, Journal of Adolescent Research, 22.1 pp.32-57

COCKING, DEAN \& KENNETT, JEANETTE (2000) Friendship and moral danger, The Journal of Philosophy, 97.5, pp.278-296

DEPARTMENT FOR EDUCATION (2015) Personal, social, health and economic (PSHE) education: a review of impact and effective practice (Crown)

DENHAM, SUSANNE (1998) Emotional development in young children (New York, Guilford Press)

DIXON, NICHOLAS (1995) The friendship model of filial obligations, Journal of Applied Philosophy, 12.1, pp.77-87 
DWORKIN, RONALD (1998) Law's Empire (Oxford, Hart Publishing)

EBAUGH, HELEN (1988) Becoming an ex: The process of role exit (Chicago, University of Chicago Press)

ELLIS, WENDY \& ZARBATANY, LYNNE (2007) Explaining friendship formation and friendship stability: The role of children's and friends' aggression and victimization. Merrill-Palmer Quarterly, 53.1 pp.79-104.

GILBERT, MARGARET (1999) Obligation and joint commitment, Utilitas, 11.2 pp.143-163

HALSTEAD, MARK \& TAYLOR, MONICA (2000) Learning and teaching about values: A review of recent research. Cambridge Journal of Education, 30.2, pp.169-202.

HARDIMON, MICHAEL (1994) Role obligations, The Journal of Philosophy, 91.7, pp.333-363

HERMAN, GABRIEL (1987) Ritualised friendship and the Greek city (Cambridge, Cambridge University Press)

HOLLINGSWORTH, HEIDI \& BUYSSE, VIRGINIA (2009) Establishing friendships in early childhood inclusive settings what roles do parents and teachers play? Journal of Early Intervention, 31.4 pp. 287-307.

HURKA, THOMAS (2013) The goods of friendship. In: D. CALUORI (ed.) Thinking about Friendship: Historical and Contemporary Philosophical Perspectives (Basingstoke; New York: Palgrave Macmillan)

JESKE, DIANE (1997) Friendship, virtue, and impartiality, Philosophy and Phenomenological Research, LVII.I, pp.51-72

NEHAMAS, ALEXANDER (2010) XII-The good of friendship, Proceedings of the Aristotelian Society 110.3 .3$, pp.267-294

PANGLE, LORRAINE (2003) Aristotle and the philosophy of friendship (Cambridge, Cambridge University Press)

PROULX, MARIE-FRANCE \& POULIN, FRANCOIS (2013) Stability and change in kindergartners' friendships: examination of links with social functioning. Social Development, 22, pp. 111125.

RAILTON, PETER (1984) Alienation, consequentialism, and the demands of morality Philosophy \& Public Affairs, 13.2, pp.134-171

ROSENBURY, LAURA (2007) Friends with benefits? Mitchigan Law Review, 106.2 pp. 189-242.

SELMAN, ROBERT (1980) The growth of interpersonal understanding (New York, Academic Press)

SEYFARTH, ROBERT \& CHENEY, DOROTHY (2012) The evolutionary origins of friendship, Annual review of psychology, 63, pp.153-177

SNELL, PATRICIA \& ENGLANDER, ELIZABETH (2010) Cyberbullying victimization and behaviors among girls: applying research findings in the field, Journal of Social Sciences, 6, pp.510-514

STERN-GILLET, SUZANNE (1995) Aristotle's Philosophy of Friendship (New York, State University of New York Press)

STOCKER, MICHAEL (1981) Values and purposes: the limits of teleology and the ends of friendship, The Journal of Philosophy, 78.12, pp.747-765

SUTTON, JOHN (2012) Memory The Stanford Encyclopedia of Philosophy (Winter 2012 Edition), Edward N. Zalta (ed.), URL = <http://plato.stanford.edu/archives/win2012/entries/memory/>

TELFER, ELIZABETH (1970) Friendship, Proceedings of the Aristotelian Society, 71, pp.223-241

WELLER, SUSIE (2007) 'Sticking with your Mates?'Children's friendship trajectories during the transition from primary to secondary school. Children \& society, 21.5, pp. 339-351.

WHITE, RICHARD (1999) Friendship and commitment, The Journal of Value Inquiry, 33.1 pp.79-88 